\title{
Strong decline of gene diversity in local populations of the highly endangered Common hamster (Cricetus cricetus) in the western part of its European range
}

\author{
M. J. J. La Haye • K. Neumann • H. P. Koelewijn
}

Received: 8 December 2010/Accepted: 23 September 2011/Published online: 20 October 2011

(C) The Author(s) 2011. This article is published with open access at Springerlink.com

\begin{abstract}
The Common hamster (Cricetus cricetus) has declined by more than $99 \%$ in the westernmost part of its range in Belgium, the Netherlands and the adjacent German federal state of North Rhine-Westphalia (BNN region) during recent decades. Various conservation schemes are ongoing to support the remaining populations, including restoration of the habitat, captive breeding and reintroductions. One of the factors determining the success of conservation actions is the genetic constitution of the remaining populations. We therefore measured the genetic variation in current BNN hamster populations and compared the outcome with the genetic variation in museum samples from the historical, non-fragmented, population. Most of the current populations have lost the majority of their rare alleles and individual animals have become nearly homozygous. Since different alleles became fixed in
\end{abstract}

Electronic supplementary material The online version of this article (doi:10.1007/s10592-011-0278-x) contains supplementary material, which is available to authorized users.

M. J. J. La Haye $(\bowtie)$

Department of Animal Ecology and Ecophysiology, Institute for Wetland and Water Research, Radboud University Nijmegen, Toernooiveld 1, 6525 ED Nijmegen, The Netherlands e-mail: Maurice.lahaye@wur.nl

M. J. J. La Haye

ALTERRA-Wageningen UR, Centre for Ecosystems Studies, P.O. Box 47, 6700 AA Wageningen, The Netherlands

\section{K. Neumann}

Institute of Pathology/Molecular Diagnostics Section, Medical Centre Dessau-Rosslau, Auenweg 38, 06847 Dessau, Germany

H. P. Koelewijn

Nunhems Netherlands BV, P.O. Box 4005, 6080 AA Haelen, The Netherlands different populations, this has resulted in strong genetic differentiation between current populations and reflects the strength of drift and inbreeding processes in small and isolated populations. Despite this differentiation, the total gene diversity of these small populations combined is not much less than that of the historical population. Hence, the main genetic difference between historical and present is not in terms of total genetic variation or number of alleles in the BNN region, but in the distribution of this variation over the populations.

Keywords Conservation strategy · Fragmentation $\mathrm{F}_{\mathrm{ST}} \cdot$ Historical samples $\cdot$ Population differentiation

\section{Introduction}

The Common hamster (Cricetus cricetus), a medium-sized rodent, has a distribution that ranges from Siberia to Western Europe (Fig. 1, based on Mitchell-Jones et al. 1999). In the last decades the species has declined dramatically throughout Europe (Nechay 2000), especially in the westernmost part of its range (Belgium, the Netherlands and the adjacent German federal state of North RhineWestphalia, henceforth referred to as the BNN region) where only a few relict populations survive. The population of the BNN region is geographically separated from other European populations, with the nearest populations in France and central Germany. The decline has led to the strict protection of the species within Europe. Currently numerous conservation schemes are ongoing to support the remaining populations, including restoration of the habitat, and captive breeding and reintroductions (Müskens et al. 2008; Sander and Weinhold 2008; Verbist 2008). The success of conservation measures depends on many factors, 
the most prominent being farming practices, availability of suitable habitat and genetic makeup of the populations ( $\mathrm{La}$ Haye et al. 2010). Here, we focus on the genetics of the hamster populations in Belgium, the Netherlands and the German federal state of North Rhine-Westphalia: the BNN region.

Population genetic theory on declining and small populations predicts a loss of gene diversity and fixation of alleles as a result of inbreeding and drift (Allendorf 1986; Frankham et al. 2002) and, consequently, increased population differentiation. The loss of gene diversity could come about by either (i) the extinction of alleles due to sampling in small populations, (ii) inbreeding reducing heterozygosity by redistributing gene diversity among homozygous individuals and populations, and (iii) selection favouring one allele at the expense of others, leading to fixation (Frankham et al. 2002; Allendorf and Luikart 2007). Since the hamster is short-lived and has a high reproductive rate and the current population sizes in the BNN region are small, the species could be vulnerable to inbreeding and rapid loss of gene diversity in the current populations.

The expected limited genetic variation among the last remaining individuals could also have consequences for breeding programs. In the Netherlands, for example, the breeding and reintroduction programme could be hampered because the programme was started with 14 individuals trapped in the last remaining Dutch population. As a result, the genetic variation in the Dutch hamster breeding stock is
Fig. 1 Geographical distribution of the Common hamster (Cricetus cricetus) in Europe according to MitchellJones et al. (1999) and a detailed map of the BBN region. Sampled historical Belgian and Dutch population: grey area, H1-H2. Sampled current populations: black dots, R1-R5

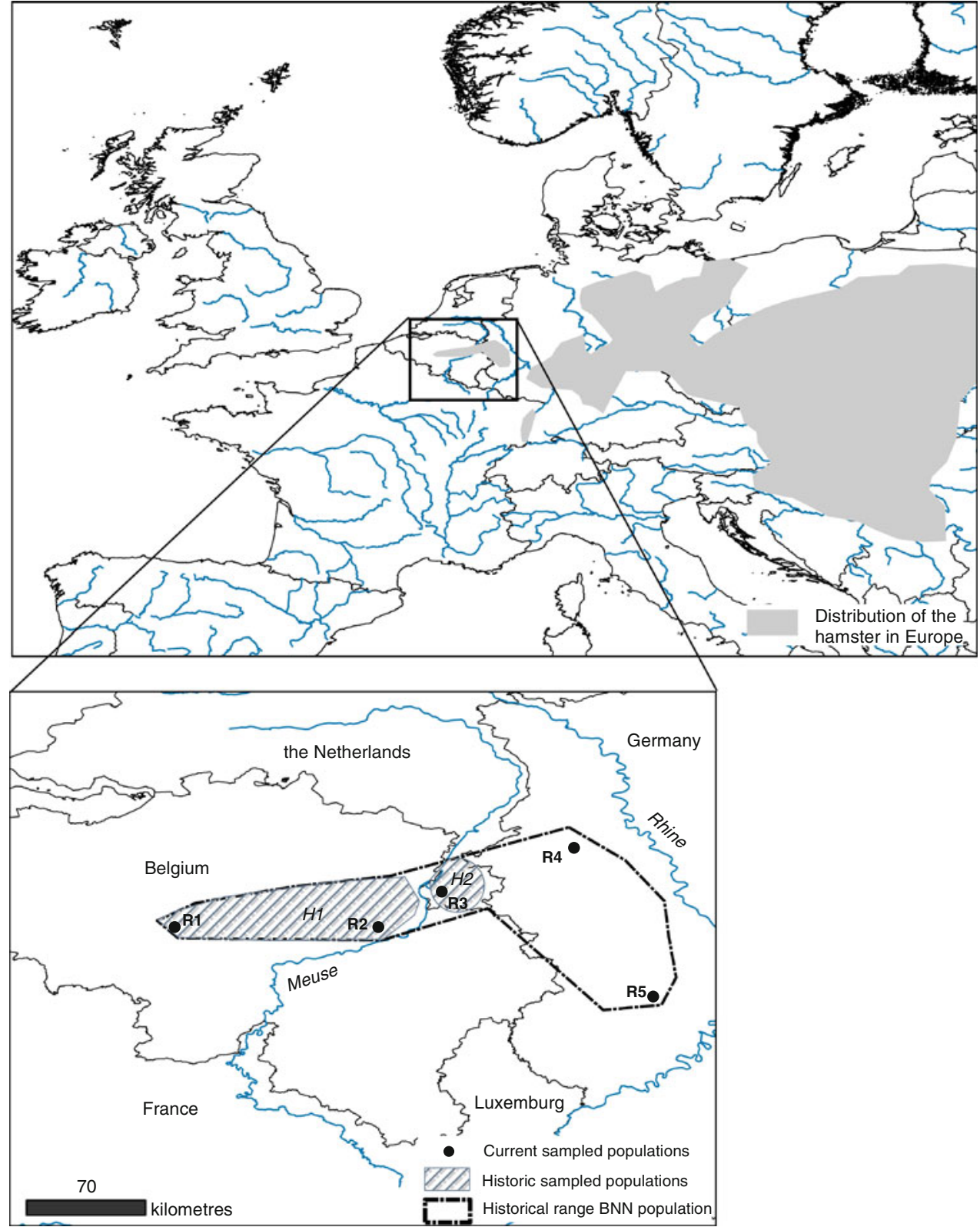


limited and the hamsters were probably already inbred. This limited genetic variation and the unavoidable further inbreeding in the captive population may have negative effects, such as smaller litters or a reduced longevity, which will affect the long-term persistence of the species in captivity and threaten the success of reintroduction in the wild (Frankham et al. 2002). Increasing gene diversity by introducing hamsters from other populations is the most likely effective way to counteract the negative effects of inbreeding (Tallmon et al. 2004; Bouzat et al. 2009), but crossings with hamsters from other populations can also lead to outbreeding depression or other negative effects (Hedrick 2001). Therefore, in order to select appropriate donor populations it is necessary to measure the gene diversity and differentiation of potential donor populations.

The genetic spatial structure of the Common hamster in Europe and the gene diversity of western European populations has been previously analysed in Neumann et al. (2004) and Neumann et al. (2005), showing that gene diversity of European hamster populations has been caused by repeated range expansions from eastern refugia. The populations from Belgium, the Netherlands, France and Germany belong to the 'Northern' group, whereas populations from Czech republic and Hungary belong to the 'Southern' group Pannonia. Within this 'Northern' group several geographical distinguishable populations can be recognized in central Germany (SaxonyAnhalt), France (Alsace), Belgium, the Netherlands and the German federal state of North Rhine-Westphalia (BBN region). These studies also suggest that the Rhine valley was used as a post-glacial migration corridor for western populations, causing historic founder effects when groups of hamsters colonised new areas. Neumann et al. (2004) also showed that variation in mitochondrial DNA is very limited in western European hamster populations and these populations are predominantly of only a single haplotype, we therefore used only nuclear microsatellite DNA for our study.

The objectives of our study were to deduce the effects of the recent population collapse on the gene diversity in Common hamster populations in the $\mathrm{BNN}$ region. We compared the genetic variation of the currently surviving populations in the BNN region with the gene diversity from museum samples collected in the same region. The museum specimens were treated as an undisturbed population from the past, which served as a reference to interpret the current patterns of genetic differentiation and diversity of the relict populations in the BNN region (Matocq and Villablanca 2001; Biedrzycka and Konopinski 2008; Hulova and Sedlacek 2008). In doing so, we were able to (1) quantify the loss of genetic variation in individual populations in the BNN region, (2) reveal how the combined effects of inbreeding and drift have influenced current population differentiation patterns, and (3) formulate advice on how to manage gene diversity of hamster populations in the BNN region.

\section{Materials and methods}

Samples and genotyping

Our study is based on 250 samples from populations in the BNN region $(n=85)$, France $(n=68)$ and a population in central Germany $(n=97)$. The samples from the BNN region consisted of 52 samples from the five currently surviving populations in Belgium, the Netherlands and North Rhine-Westphalia and 33 samples from museum specimens. The sample sizes from the current populations in the BNN region (R1-R5) were unavoidably small because of the small population sizes and the current rarity of the hamster in the BNN region. Since 2002 reintroductions and restocking of hamsters have taken place in the Netherlands and Belgium, but samples of these managed populations were excluded from our study. The samples from France and central Germany were included because they provide a reference for an estimate of gene diversity in vital populations of the hamster and were part of a phylogeographic study for suitable donor populations.

The museum samples consisted of pieces of dried skin, sometimes including hairs, that were taken from museum specimens that were collected or found in the wild in Belgium and the Netherlands during the period 1925-1985; 85\% of the specimens were collected before 1970. Unfortunately, no samples were available from the historical populations of North Rhine-Westphalia. In total 51 museum specimens from the museums of natural history in Leiden (Naturalis, the Netherlands) and Brussels (KBIN, Belgium) were sampled, but only 33 samples provided sufficient enough DNA for PCR amplification. The technical analysis of museum and current samples is described in detail in Neumann and Jansman (2004). All genotyping was done by the second author at the Institute of Zoology of the Martin-Luther University in Halle-Wittenberg, Germany.

The museum specimens originated from across the historical range in both countries and represent the historical continuous population in Belgium and the Netherlands. However, the Belgian and Dutch populations have been separated from each other by the river Meuse for centuries, which suggests there was at least some isolation (Fig. 1) and perhaps migrants only exchanged during rare mass outbreaks. We therefore assigned each sample either to the historical hamster population of Belgium $(n=8, \mathrm{H} 1)$ or to the historical population of the Netherlands $(n=25, \mathrm{H} 2)$ (see Table 1 for population characteristics).

Our samples of the current populations in the BNN region were collected during the period 1997-2005 and consisted of 52 hair and tissue samples. Samples were collected in different years or from dead individuals, which excludes the possibility that individuals were sampled several times. The samples were collected from (i) two hamster populations in Belgium 
Table 1 The hamster populations studied: code, origin, number of samples, and period from which the sampled hamsters dated

\begin{tabular}{llcr}
\hline Code & Population & \# Samples & Period \\
\hline Historical (museum samples) & & & \\
H1 & Belgium & 25 & $1929-1985$ \\
H2 & Netherlands & & $1925-1980$ \\
Recent (hair and tissue samples) & & 10 & $2000-2005$ \\
R1 & Belgium-Brabant & 8 & $2001-2005$ \\
R2 & Belgium-Tongeren & 15 & $1997-1999$ \\
R3 & Netherlands & 8 & $2003-2005$ \\
R4 & NRW-Neuss, Germany & 11 & 1999 \\
R5 & NRW-Zülpich, Germany & & $1999-2000$ \\
Reference & & 68 & $1994-2000$ \\
RF6 & Alsace, France & 97 & \\
RF7 & Saxony-Anhalt, Germany & \\
\hline
\end{tabular}

(R1: $n=10$, R2: $n=8$; Table 1$)$, with population size estimates varying from 6 to 20 individuals based on burrow findings in recent years (Verbist 2008); (ii) the last wild population from the Netherlands (R3: $n=15$; Table 1) of which 14 individuals were trapped (almost the entire population) and brought into captivity in 1999, and one sample from 1997 taken from a dead hamster found at the same location; and (iii) two relict populations in North RhineWestphalia, Germany (R4: $n=8, \mathrm{R} 5: n=11$; Table 1), with estimated populations of $<100$ and $<200$ individuals, respectively (Pauly 2007). The samples were collected in geographically distinct populations at least $30 \mathrm{~km}$ apart and with no known populations in between. All the current populations are probably completely isolated from each other, because their distance apart $(>30 \mathrm{~km})$ far exceeds the natural dispersal capacity of $1.5 \mathrm{~km} /$ year in this species (Ulbrich and Kayser 2004).

All samples were genotyped for a maximum of 11 microsatellite loci: $\operatorname{Ccr} \mu 3, \operatorname{Ccr} \mu 4, \operatorname{Ccr} \mu 6, \operatorname{Ccr} \mu 10, \operatorname{Ccr} \mu 11, \operatorname{Ccr} \mu 12$, $\operatorname{Ccr} \mu 13, \operatorname{Ccr} \mu 15, \operatorname{Ccr} \mu 17, \operatorname{Ccr} \mu 19$, and $\operatorname{Ccr} \mu 20$. However, in our study we used only 9 of the 11 available microsatellites because there were too many missing values at loci $\operatorname{Ccr} \mu 6$ and/ or $\operatorname{Ccr} \mu 19$, especially in the museum samples. Museum samples with less than 6 known loci were excluded from the analysis. Almost half of the 33 museum samples showed missing values ( $n=17,51 \%$ ), with 8 samples missing 1 locus, 8 samples missing 2 loci and 1 sample missing 3 loci.

Gene diversity, genetic divergence and population differentiation

To characterise within-population diversity, we determined the fraction of polymorphic loci, the average number of alleles, allelic richness, the observed and expected heterozygosity (i.e. gene diversity) using the programs GenAlEx (Peakall and Smouse 2006) and Genepop (Raymond and
Rousset 1995). MICROCHECKER version 2.2.3 (Oosterhout et al. 2004) was used to detect the presence of null alleles and dropouts. Wright's F-statistics (Wright 1978) were used to compare the degree of genetic subdivision between populations. Population differentiation was determined with the FSTAT program (Goudet 1995).

To infer recent changes in population size we studied the distribution of allele frequencies (Luikart et al. 1998) using the Bottleneck software (Piry et al. 1999; mode-shift indicator, which discriminates bottlenecked populations from stable populations with L-shaped distribution of alleles). Changes in the expected heterozygosity between current and past populations can also be used to estimate the effective inbreeding coefficient $\left(F_{e}\right)$ of the current populations: $F_{e}=1-H_{\text {recent }} / H_{\text {historical }}$ (Frankham et al. 2002; Allendorf and Luikart 2007; Hamilton 2009), which is the level of inbreeding that has accumulated over time.

To visualise population differentiation we carried out a Principal Coordinate Analysis (PCA) of the genetic distance matrices for the total dataset and for the subset of populations from the BNN region, using GenAlEx (Peakall and Smouse 2006). Using the Structure program (Pritchard et al. 2000) we obtained an estimate of the probable number of independent genetic clusters (k) in our dataset. This approach does not require a priori information about population structure and thus provides an estimate of genetic structure independent of the origin of samples. We used the no-admixture algorithm without prior population information and used 50,000 runs as burn-in and 500,000 runs for each of three Markov chains. First, we pooled the populations in order to detect the genetic structure of the hamster at an European scale. For each simulation of $k=1-9$ (no. of clusters), we used ten replicates. The simulation of $\mathrm{k}$ that resulted in the lowest log-likelihood was chosen as representing the dataset best. Next, we determined the most likely assignment of each sample to 
the clusters, on the basis of the prior population information. Subsequently, we used Structure to detect local population structure in the BNN populations only (Netherlands, Belgium and North Rhine-Westphalia), using the same parameters but with $k=1-7$.

\section{Results}

\section{Genotyping}

We did not detect amplification difficulties and had no problems genotyping recent samples (R1-R5). Full genetic profiles could already be obtained from samples with two hairs. However, samples with less than ten hairs had a low overall success rate and logistic regression indicated that at least ten hairs should be used for repeatable genotypic results.

Since both museum and samples with only a few hairs could provide DNA of low quantity and quality we run replicate PCRs (range 2-4) for those samples from which sufficient DNA was available to get frequency estimates of dropouts and false alleles (cf. Broquet et al. 2007). Dropout frequency was on average $0.6 \%$, range $0 \%$ (locus 17)-5.6\% (locus 10), and the frequency of false alleles ranged from $0 \%$ (locus $11 / 12 / 17$ ) to $8 \%$ (locus 15 ) and was on average $1.8 \%$.

\section{Allelic variation}

The number of alleles and allelic richness of hamster populations in the BNN region (H1-H2: \# alleles 17-24, $\mathrm{R}_{\mathrm{s}}$ 1.8-2.0 respectively $\mathrm{R} 1-\mathrm{R} 5$ : \# alleles $\left.10-18, \mathrm{R}_{\mathrm{s}} 1.1-1.9\right)$ was lower compared to the reference populations (RF6: \# alleles 41, $\mathrm{R}_{\mathrm{s}} 2.6$ resp. RF7: \# alleles 72, $\mathrm{R}_{\mathrm{s}} 4.1$ ) (Table 2). The fraction of polymorphic loci did not differ much between the historical population in the BNN region (H1$\mathrm{H} 2$ : 0.89 ) and the reference populations (1.0). But the fraction of polymorphic loci in the current BNN populations ranged from very low in R1 and R2 (only one polymorphic locus), to moderate in R5 (six polymorphic loci out of a total of nine loci). The low number of alleles and the limited allelic richness was reflected in low observed and expected heterozygosities in R1-R4 (0.01-0.16). An exception is R5, the Zülpich population, which has a relatively high number of alleles (total number of alleles $=18)$ and allelic richness $\left(\mathrm{R}_{\mathrm{s}}=1.9\right)$ and the highest observed and expected heterozygosity $(0.31$ and 0.29 ) of the current BNN populations.

Comparing the number of alleles in populations R1-R3 with their historical founder populations $\mathrm{H} 1$ and $\mathrm{H} 2$ (Table 2) made it possible to quantify the loss of allelic diversity. At least six (35\%) out of 17 alleles have been lost in R1 and R2 compared to $\mathrm{H} 1$, and $11(46 \%)$ out of 24 alleles have been lost in R3 compared to H2. No samples were available from the historical populations of R4 and R5 to calculate the loss of alleles in these populations.

Alleles with a low frequency in the historical populations $\mathrm{H} 1$ and $\mathrm{H} 2$ were more often absent in their current populations R1, R2 and R3 (Fig. 2). The allele frequency distribution of R3 showed the signature of a recent bottleneck and deviated significantly $(P<0.01)$ from the $\mathrm{L}$-shaped distribution expected in populations in mutationdrift equilibrium, such as its historical population $\mathrm{H} 2$ (Fig. 3). However, the results should be taken with caution because of the low sample-sizes, H2 $n=25$ and R3 $n=15$.

For the comparison R1 and R2 versus $\mathrm{H} 1$ the pattern was less obvious, due to the presence of many non-polymorphic loci.

The low heterozygosity in the current populations compared with their historical populations (Table 2), resulted in high effective inbreeding coefficients, both in Belgium and the Netherlands $\left(F_{e}, \mathrm{R} 1+\mathrm{R} 2-\mathrm{H} 1\right.$ (Belgium): 0.94, R3-H2 (Netherlands): 0.43).

$\mathrm{H} 1$ and $\mathrm{H} 2$ deviated significantly from HW proportions, as did the different combinations of BNN-populations $(\mathrm{H} 1+\mathrm{H} 2, \mathrm{R} 1+\mathrm{R} 2+\mathrm{R} 3, \mathrm{R} 4+\mathrm{R} 5$ and $\mathrm{R} 1+\mathrm{R} 2+\mathrm{R} 3$ $+\mathrm{R} 4+\mathrm{R} 5)$.

\section{Population differentiation}

Comparing the genetic variation of the historical hamster populations $\mathrm{H} 1$ and $\mathrm{H} 2$ with the combined genetic variation of their current populations R1, R2 and R3 revealed that the total gene diversity, as indicated by the expected heterozygosity (Nei 1987), has declined slightly (Table 2). Most of the gene diversity in the populations of Belgium $(\mathrm{R} 1+\mathrm{R} 2)$ and the Netherlands (R3) is still present. It is the distribution among populations that has changed. Almost all of the current BNN populations, except R5, show very low observed heterozygosities and low $\mathrm{F}$ values, but the combined BNN populations (R1-R5, Table 2) show very high $F$ values and deviations from HWE. These results indicate a strong Wahlund effect. Most of the current populations in the BNN region consist of genetically near-homozygous populations with different gene diversity fixed in different populations.

A PCA-analysis of our samples showed a strong population differentiation at a European level (Fig. 4a) with a strong clustering of the samples from Saxony-Anhalt (RF7) and Alsace (RF6) and a more scattered cluster with the $\mathrm{BNN}$-samples. The $\mathrm{F}_{\mathrm{ST}}$ among these populations was 0.34 , indicating large differences in genetic composition among the populations on a European scale. 


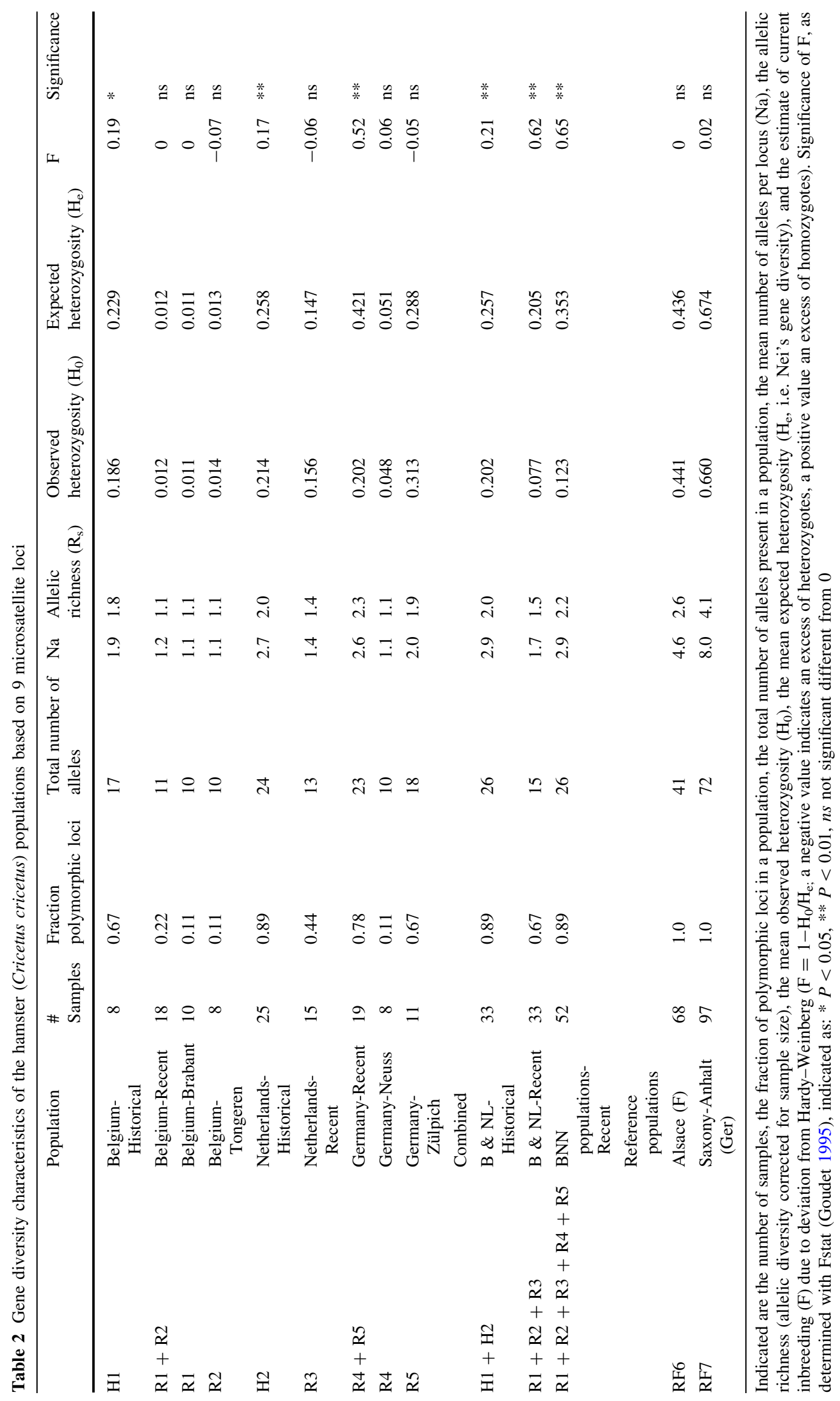




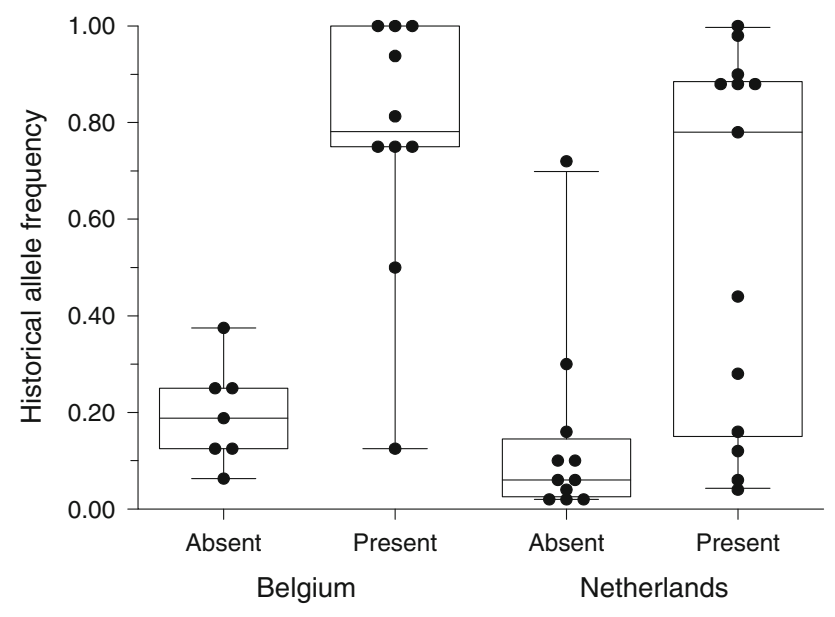

Fig. 2 Loss of alleles as a function of the historical allele frequency. Alleles were classified as being absent or present in the current hamster populations in Belgium or Netherlands. In the box-whisker plots the horizontal line within the box is the median value, the dots indicate the individual alleles. Logistic regression on presence/ absence indicated a significant effect of historical allele frequency $(P<0.001)$ and no difference in this relationship between the two countries

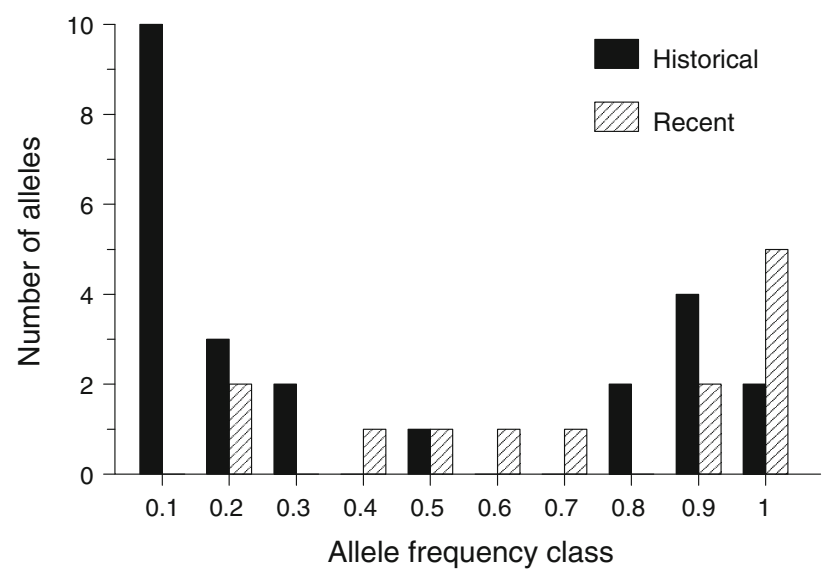

Fig. 3 Allele frequency distributions from the historical $(\mathrm{H} 2$, $n=25)$ and recent (R3, $n=15)$ Dutch hamster populations

A more detailed analysis of only the BNN samples (Fig. 4b) showed that this cluster consists of several small discrete clusters. Strikingly, the historical populations $\mathrm{H} 1$ and $\mathrm{H} 2$ grouped together, while the samples from the current populations seem to have diverged and form distinct groups, with the exception of R1 and R2 (the two current Belgian populations) which also cluster together. The $\mathrm{F}_{\mathrm{ST}}$ among the populations within the BNN cluster was 0.38 , but $\mathrm{F}_{\mathrm{ST}}$ values between two populations varied enormously (Table $3 b$ ). The lowest $\mathrm{F}_{\mathrm{ST}}$ values were between $\mathrm{H} 1$ and $\mathrm{H} 2(0.05, \mathrm{~ns})$ and $\mathrm{R} 1$ and $\mathrm{R} 2(0.001, \mathrm{~ns})$. However, most of the $\mathrm{F}_{\mathrm{ST}}$ values between two populations were higher and were significantly different from zero. The
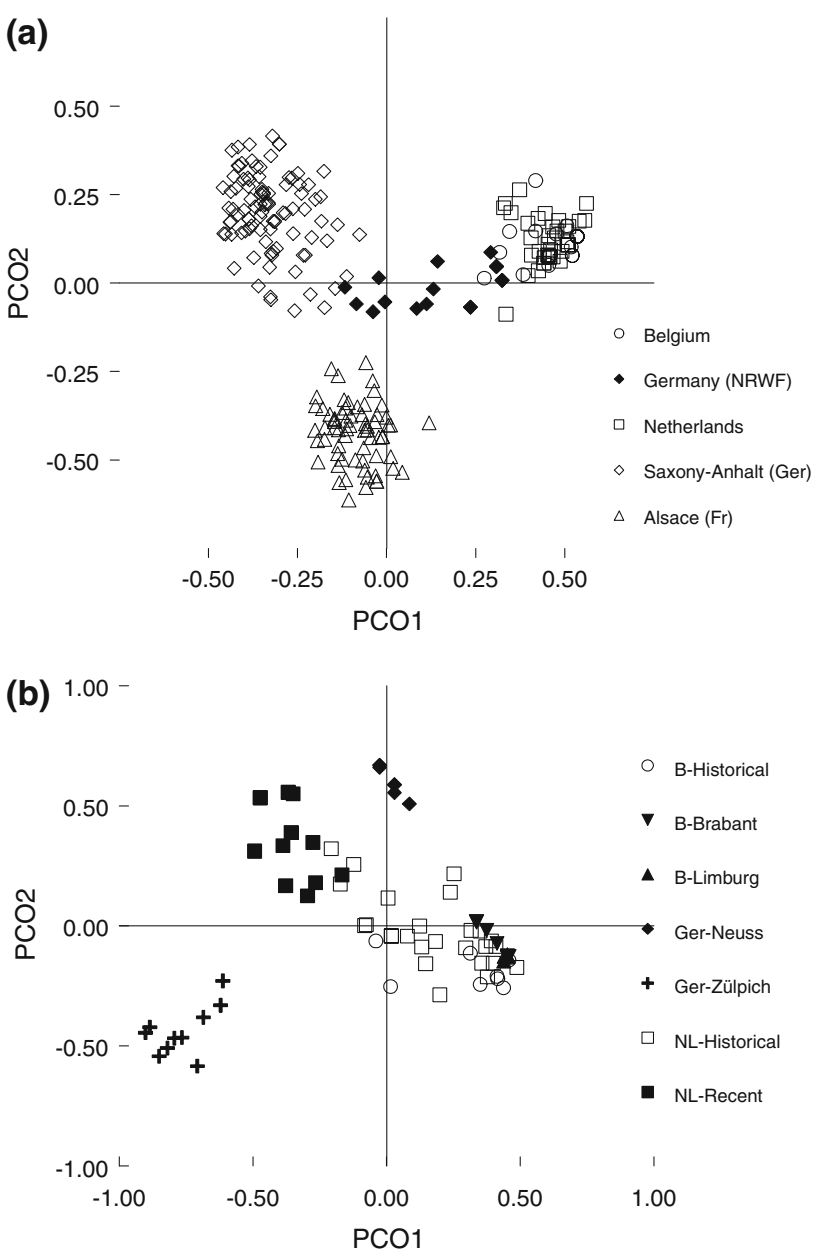

Fig. 4 Principal Coordinate Analysis on the genetic distance matrix of a the complete dataset including the reference populations SaxonyAnhalt and Alsace, and $\mathbf{b}$ the subset of the populations in Belgium, The Netherlands and the adjacent German federal State of North Rhine-Westphalia. Shown are the scores on the first and second principal coordinates

high $\mathrm{F}_{\mathrm{ST}}$ values indicate substantial differences among most of the BNN populations, even though they are considered as one genetic cluster at a higher European level (Fig. 4a). The results from the full F-analysis (Table 3a) indicate that in the past the main contribution to the total inbreeding among the BNN populations was due to moderate inbreeding within the populations $\left(\mathrm{F}_{\mathrm{IS}}\right)$; currently the most important contribution comes from the differentiation among the populations $\left(\mathrm{F}_{\mathrm{ST}}\right)$, a direct consequence of random genetic drift.

A Bayesian cluster analysis with the Structure program indicated that the most likely number of clusters from the total dataset of nine populations (Table 1) was four $(K=4)$. The assignment of the individual samples to the four clusters confirmed the PCA results: Saxony-Anhalt, Alsace and the BNN region were correctly identified, with 
Table 3 (a) Results from a F-statistics analysis on the historical and current population data from the BNN region. (b) Pair wise $\mathrm{F}_{\mathrm{ST}}$ estimates between the BNN populations, in bold those estimates that were significantly different from zero with $P<0.05$ after Bonferroni correction $(n=21)$

\begin{tabular}{|c|c|c|c|c|c|c|c|c|}
\hline & & & $\mathrm{F}_{\mathrm{IT}}$ & & & & & $\mathrm{F}_{I S}$ \\
\hline $\mathrm{a}$ & & & & & & & & \\
\hline His & opulations (H1 and H2) & & 0.249 & & & & & 0.21 \\
\hline Cur & pulations (R1, R2, R3) & & 0.722 & & & & & -0.01 \\
\hline & $\mathrm{F}_{\mathrm{ST}}$ of each population pair & $\mathrm{H} 1$ & $\mathrm{H} 2$ & R1 & $\mathrm{R} 2$ & R3 & R4 & R5 \\
\hline $\mathrm{b}$ & & & & & & & & \\
\hline H1 & Belgium-Historical & $\mathrm{X}$ & ns & ns & ns & ns & ns & ns \\
\hline $\mathrm{H} 2$ & Netherlands-Historical & 0.047 & $\mathrm{X}$ & $*$ & $*$ & $*$ & $*$ & $*$ \\
\hline R1 & Belgium-Brabant & 0.228 & 0.139 & $\mathrm{X}$ & ns & $*$ & $*$ & $*$ \\
\hline $\mathrm{R} 2$ & Belgium-Tongeren & 0.207 & 0.140 & 0.001 & $X$ & $*$ & $*$ & $*$ \\
\hline R3 & Netherlands-Recent & 0.552 & 0.391 & 0.728 & 0.718 & $\mathrm{X}$ & $*$ & $*$ \\
\hline $\mathrm{R} 4$ & Germany-Neuss & 0.642 & 0.499 & 0.911 & 0.903 & 0.688 & $\mathrm{X}$ & $*$ \\
\hline R5 & Germany-Zülpich & 0.536 & 0.510 & 0.710 & 0.696 & 0.564 & 0.700 & $\mathrm{X}$ \\
\hline
\end{tabular}

$\mathrm{F}_{\mathrm{IT}}=$ the total inbreeding in a population, due to both inbreeding within subpopulations, and differentiation among subpopulations; $\mathrm{F}_{\mathrm{ST}}=$ the proportion of the total inbreeding in a population due to differentiation among subpopulations; $\mathrm{F}_{\mathrm{IS}}=$ the proportion of the total inbreeding in a population due to inbreeding within subpopulations (i.e., departure from Hardy-Weinberg equilibrium)

Fig. 5 Population differentiation according to STRUCTURE, with a individual assignment probabilities for all samples in a combined analysis. Most likely number of genetic clusters was four $(K=4)$ and $\mathbf{b}$ individual assignment probabilities for the analysis only based on the BNN samples. Most likely number of genetic clusters was five $(K=5)$. Also indicated between brackets is the membership probability of each population to the assigned genetic cluster (legend above the figures). The $H$ and $R$ stands for historical or recent populations, respectively (a)
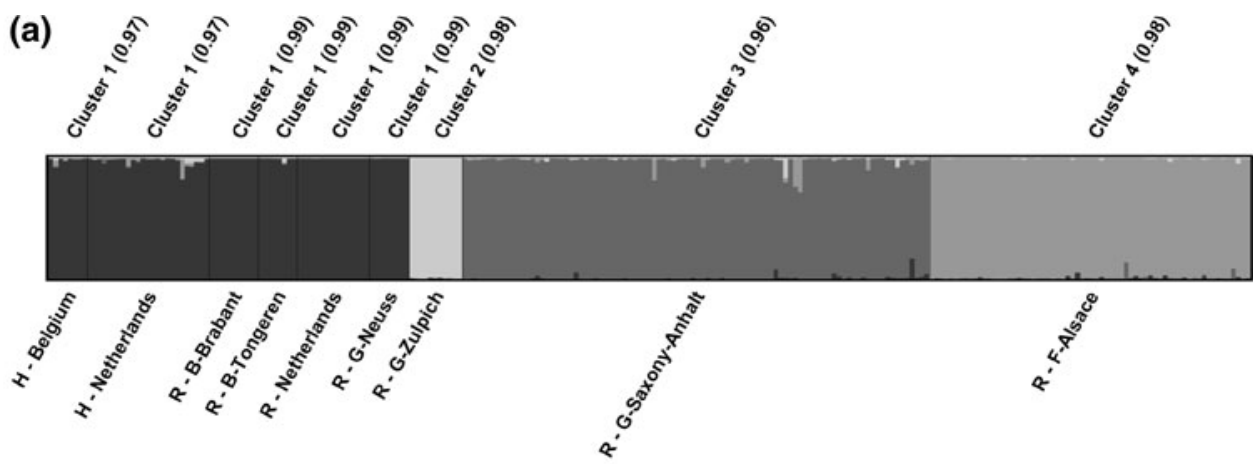

(b)
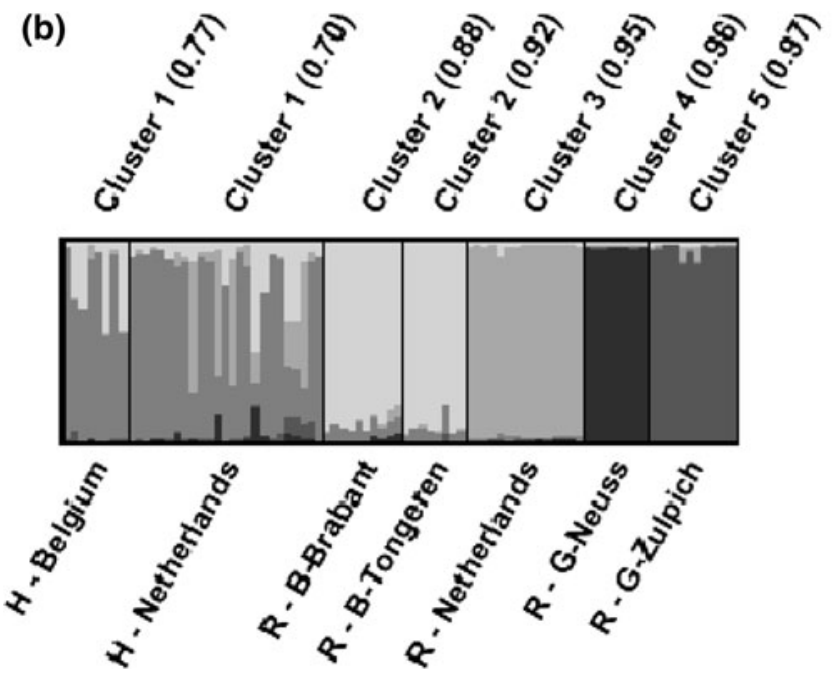

Zülpich population from North Rhine-Westphalia. The other population from North Rhine-Westphalia (R4, Neuss) was assigned to the BNN cluster. 
We also applied the Structure program to the BNN populations alone, for two reasons: because of the large differences in genetic composition of the European populations shown in the PCA figure (Fig. 4a), and to clarify the differentiation of the BNN populations (Fig. 4b). The Structure analysis confirmed the results of PCA shown in Fig. 4b: that the populations of the BNN region were highly differentiated from each other (Fig. 5b). The most likely number of clusters that the program distinguished among the seven populations was five $(K=5)$. Most of the recent populations were assigned as separate clusters, but the current Belgian populations R1 and R2 were assigned as one cluster and the historical Dutch (H2) and Belgian (H1) populations did not form separate clusters and can also be considered as one genetic cluster (Fig. 5b).

\section{Discussion}

The consequences of becoming small and isolated

Habitat fragmentation is the most important factor causing the decline of populations and loss of species in the current Dutch landscape (van Veen et al. 2010). Habitat fragmentation includes two processes, a reduction in total habitat area and creation of separate isolated patches from a larger continuous distribution. Both processes have affected and still affect the hamster population in the BNN region: the total area of suitable habitat has declined due to changed agricultural practices (Robinson and Sutherland 2002; Kuiters et al. 2010) thereby creating isolated hamster populations of which only a few remain at the moment (Fig. 1). A reduction in population size combined with an increased degree of isolation, and therefore more restricted gene-flow, will inevitably lead to a reduction in gene diversity and reduced viability of populations (Frankham et al. 2002; Allendorf and Luikart 2007). Here we have documented the processes involved with the decline of the hamster in the Netherlands and Belgium by comparing museum samples, used as an unaffected reference from the past, with samples from the last remaining populations. Our data reveal that the current populations have lost an important part of their gene diversity. This loss of gene diversity came about by (i) the extinction of (rare) alleles in the current small populations (Figs. 2, 3), (ii) inbreeding reducing heterozygosity by redistributing gene diversity among homozygous individuals and populations (Table 2), and (iii) fixation of different alleles in different populations, causing reduced polymorphism (Table 2) and strong population differentiation (drift; Table 3; Fig. 4b). These results confirm and illustrate the expectations from population genetic theory of small populations (cf. Frankham et al. 2002).
The loss of alleles has affected historical rare alleles much more than historical more frequent alleles. Figure 2 shows that the historical rare alleles of $\mathrm{H} 1$ and $\mathrm{H} 2$ were much more absent in the current populations (R1-R3) than more frequent alleles; this is typical of populations experiencing a bottleneck (Luikart et al. 1998). Surprisingly, the population of Zülpich (R5) still had a relative high heterozygosity in comparison with the other current BNN populations, which suggests either that this population once had a high allelic diversity, or that the effective population size has remained sufficiently large to prevent rare alleles being lost and to prevent a decline in heterozygosity. Unfortunately, it was not possible to measure the loss of gene diversity in North Rhine-Westphalia (R4 + R5), because we had no historical samples from these populations.

Our results reveal both a loss in alleles, allelic richness and observed and expected heterozygosity in the local populations (Table 2). At the regional scale the loss is less dramatic when considering the expected heterozygosity (i.e., gene diversity). The low number of alleles in the historical hamster populations, in comparison with the reference populations, is attributable to a prehistoric founder effect (Neumann et al. 2005), but the number of alleles has even further decreased in the current populations of the BNN region: $\mathrm{H} 2$ versus $\mathrm{R} 3$, \# alleles decreased from 24 to $13(-46 \%), \mathrm{R}_{\mathrm{s}}$ from 2.0 to 1.4 and $\mathrm{H}_{\mathrm{o}}$ from 0.21 to $0.16(-24 \%)$ and $\mathrm{H} 1$ versus $\mathrm{R} 1+\mathrm{R} 2$, \# alleles decreased from 17 to $11(-35 \%), \mathrm{R}_{\mathrm{s}}$ from 1.8 to 1.1 and $\mathrm{H}_{\mathrm{o}}$ from 0.19 to $0.01(-95 \%)$. The latter indicates that the Belgian populations ( $1+\mathrm{R} 2)$ became nearly homozygous. When considering the current Belgian and Dutch populations together $(\mathrm{H} 1+\mathrm{H} 2$ vs. $\mathrm{R} 1+\mathrm{R} 2+\mathrm{R} 3)$ the loss is limited: the \# alleles decreased from 26 to 15 ($42 \%), \mathrm{R}_{\mathrm{s}}$ from 2.0 to $1.5, \mathrm{H}_{\mathrm{o}}$ from 0.20 to $0.07(-65 \%)$ and $\mathrm{H}_{\mathrm{e}}$ decreased from 0.26 to $0.21(-19 \%)$. At the regional scale the former variation is still present, but redistributed among the different populations and not anymore present in all the local populations.

Most of the populations are currently strongly differentiated (Table 3) which indicate the strong drift effect that has taken place: populations have shifted to the edges of their original genetic distribution in various directions (Fig. 4b). Because of the strong drift effect the current BNN population consists of several distinct populations (Fig. 4b), but compared with the reference populations RF6 and RF7 these BNN populations are considered to be one cluster (Fig. 4a). The analysis of our data with Structure (Fig. 5a) confirmed this pattern: Saxony-Anhalt (RF7), Alsace (RF6) and the BNN region were identified as discrete clusters. However, Structure placed the German population of Zülpich (R5), which is geographically part of the BNN region, in a cluster of its own. Geographically, 
Zülpich is also a link between the BNN region, Alsace and central Germany hamster populations (Fig. 1). It is possible, although speculative, that Zülpich is the location where descendants of central German hamsters crossed the river Rhine and started to colonise the BNN region; this would account for the genetic similarities to Saxony-Anhalt (RF7).

The BNN populations are considered to be one cluster on a European scale, but high $\mathrm{F}_{\mathrm{ST}}$ values between current BNN populations also indicates very high genetic differentiation between populations. The current $\mathrm{F}_{\mathrm{ST}}$ values between R1 and R5 range from 0.56 till 0.91 . Our results also show that the loss of genetic variation from populations that were historically genetically very similar (H1 and $\mathrm{H} 2$ ) can result in very low and very high $\mathrm{F}_{\mathrm{ST}}$ values between descendant populations. Surprisingly, the $F_{S T}$ between the current Belgian populations R1 + R2 is very low (0.001). Both Belgian populations were genetically very similar in our analysis based on nine microsatellites, but the results at locus $\operatorname{Ccr} \mu 6$ (excluded from our analysis because of too many missing values in the museum samples) showed different alleles between the two recent populations. It is unclear why both Belgian showed the same gene diversity, but both populations descent from the same historical population (H1) with an already impoverished gene diversity. It is possible that the population in Belgian had a continuous distribution until some decades ago and that the current gene diversity is a result of very recent genetic drift. The current distance of $55 \mathrm{~km}$ between both populations makes the possibility of a recent colonisation of one of the populations by immigrants from the other population highly unlikely.

In most of the BNN populations the loss of alleles has led to almost completely homozygous populations nowadays (Table 2; Fig. 4b), which resulted in very high effective inbreeding coefficients $\left(F_{e}\right)$. The $F_{e}$ is a cumulative measure of past inbreeding and can be used for estimating either the effective population size $\left(\mathrm{N}_{\mathrm{e}}\right)$ during the past decades or the time that was needed to cause the current reduction in gene diversity. If population size is constant in each generation, the expected heterozygosity in the next generation will be (Falconer 1980): $H_{t}=[1-1 /$ $\left.\left(2 \mathrm{~N}_{\mathrm{e}}\right)\right]^{\mathrm{t}} \quad \mathrm{H}_{\mathrm{o}}$ and $\mathrm{H}_{\mathrm{t}} / \mathrm{H}_{\mathrm{o}}=\left[1-1 /\left(2 \mathrm{~N}_{\mathrm{e}}\right)\right]^{\mathrm{t}} \sim \mathrm{e}^{-\mathrm{t} / 2 \mathrm{~N}_{\mathrm{e}}}$. Since $F_{e}=1-\mathrm{H}_{\text {current }} / \mathrm{H}_{\text {past }}$ we can get an idea of either the $\mathrm{N}_{\mathrm{e}}$ or the time that was necessary to cause a reduction in heterozygosity. The strong decline of hamster populations in Belgium and The Netherlands started in the seventies (Nechay 2000) and although the reduction in gene diversity might already have started earlier an estimate of 30-40 years seems reasonable. The effective population size needed to cause the observed reduction in heterozygosity (Table 2) is 27-36 for the Netherlands, but only 5-7 for Belgium, suggesting that processes have acted much faster in Belgium.

The reduction in gene diversity will be the result of both inbreeding and drift. It is, however, not possible to disentangle the relative importance of both processes. F-analysis suggests that drift, causing the population differentiation, is currently the most important contributor to the total inbreeding (Table 3a). In the historical populations there was some inbreeding due to non-random mating (deviation from Hardy-Weinberg), but no contribution of among population differentiation. Currently, the pattern is reversed and population differentiation is the main contributor. We therefore consider drift currently the most important factor shaping the genetic structure of the hamster populations.

A profound consequence of the strong drift effect is that the relationship between geographical distance and genetic distance of the populations has changed. The historical and large reference populations displayed a pattern of isolation by distance $(r=0.87, n=6, P<0.05)$, indicating that nearby populations were more related, most likely as the result from gene flow. Currently, the relationship is nonexistent anymore $(r=-0.03, n=16, \mathrm{~ns})$; nearby populations are as different from each other as populations far away. Thus, the large scale population structure has shifted from one being in gene flow-drift equilibrium, to one dominated by non-equilibrium conditions with strong drift effects (Hutchison and Templeton 1999).

\section{Implications for conservation projects}

It is possible that the loss of gene diversity may hamper the recovery of individual hamster populations in the BNN region (Frankham et al. 2002). Increasing the genetic variation in current BNN populations is therefore strongly recommended. Exchange or immigration of hamsters between one or two populations in the BNN region will lead to an increase of the allelic diversity, an increase of the heterozygosity and less inbreeding, even though all the populations are inbred themselves (Edmands 2007). However, exchange of hamsters between one or two populations is not enough to restore the genetic variation to the historical level prior to the population crash. Only if hamsters are exchanged between all BNN populations will it be possible to restore the historical level of genetic variation. Translocation of hamsters from other European populations, from Saxony-Anhalt or Alsace for example, into the current BNN populations will also immediately and effectively increase the genetic variation, but it will also lead to mixing of populations with a clearly different gene diversity (Neumann et al. 2004, 2005) and is therefore not recommended. 
In our opinion, exchanging hamsters between all BNN populations should include hamsters from the population of Zülpich. Although this population is genetically quite distinct, it is clearly part of the BNN population based on geography and the PCA figure. Ideally the exchange of hamsters between BNN populations, as already has been done in the Netherlands and Belgium, should be accompanied beforehand by experimental breedings to explore possible outbreeding effects. However, population numbers are currently so small that it is very difficult to trap even a few individuals in the current BNN populations. Individual quality of trapped hamsters seems therefore much more important than outbreeding depression effects as a consequence of mixing different populations. Besides, some decades ago the BNN population had a continuous distribution and the recent population fragmentation seems too short to have resulted in serious genetic differences between populations to cause outbreeding effects when mixing those populations again.

A natural recovery of the genetic variation in the current BNN populations as a result of immigrants is impossible. Hence, other measures like captive breeding and augmentations are needed to restore the gene diversity of the BNN populations. However, most important is immediate conservation of the current hamster populations in the BNN region, because extinction of one of the current populations would mean the loss of irreplaceable gene diversity, with possibly negative consequences for the long-term persistence of the species in this part of its European range.

Acknowledgements We thank Dr. Georges Lenglet of the Museum of Natural History in Brussels (KBIN, Belgium) and Ing. Hein van Grouw from the Museum of Natural History in Leiden (Naturalis, the Netherlands) for granting permission to collect museum samples. Prof. Dr. H. Siepel, Dr. L. Kuiters, Dr. W. Verberk and Dr. J. Windig provided useful comments on earlier drafts of this paper. H. Jansman collected an important part of the samples and R. Huiskes drew some graphs. We also thank our European colleagues involved in hamster research for providing the samples from other populations and the Dutch Ministry of Agriculture, Nature and Food Quality is gratefully acknowledged for funding this research project (Program BO-02-013: Active policy on species management). Dr. J. Burrough corrected our English.

Open Access This article is distributed under the terms of the Creative Commons Attribution Noncommercial License which permits any noncommercial use, distribution, and reproduction in any medium, provided the original author(s) and source are credited.

\section{References}

Allendorf FW (1986) Genetic drift and the loss of alleles versus heterozygosity. Zoo Biol 5:181-190

Allendorf FW, Luikart G (2007) Conservation and the genetics of populations. Blackwell Publishing, USA
Biedrzycka A, Konopinski MK (2008) Genetic variability and the effect of habitat fragmentation in spotted suslik Spermophilus suslicus populations from two different regions. Conserv Genet 9:1211-1221

Bouzat JL, Johnson JA, Toepfer JE, Simpson SA, Esker TL, Westemeier RL (2009) Beyond the beneficial effects of translocations as an effective tool for the genetic restoration of isolated populations. Conserv Genet 10:191-201

Broquet T, Ménard N, Petit E (2007) Noninvasive population genetics: a review of sample source, diet, fragment length and microsatellite motif effects on amplification success and genotyping error rates. Conserv Genet 8:249-260

Edmands S (2007) Between a rock and a hard place: evaluating the relative risks of inbreeding and outbreeding for conservation and management. Mol Ecol 16:463-475

Falconer DS (1980) Introduction to quantitative genetics. Longman, New York

Frankham R, Ballou JD, Briscoe DA (2002) Introduction to conservation genetics. Cambridge University Press, Cambridge

Goudet J (1995) FSTAT: a computer program to calculate F-statistics. J Hered 86:485-486

Hamilton MB (2009) Population genetics. Wiley-Blackwell, West Sussex

Hedrick PW (2001) Conservation genetics: Where are we now? Trends Ecol Evol 16:629-636

Hulova S, Sedlacek F (2008) Population genetic structure of the European ground squirrel in the Czech Republic. Conserv Genet 9:615-625

Hutchison DW, Templeton AR (1999) Correlation of pairwise genetic and geographic distance measures: inferring the relative influences of gene flow and drift on the distribution of genetic variability. Evolution 50:1898-1914

Kuiters L, La Haye M, Müskens G, van Kats R (2010) Perspectieven voor een duurzame bescherming van de hamster in Nederland (in Dutch with English summary). Rapport Alterra, Wageningen

La Haye MJJ, Müskens GJDM, van Kats RJM, Kuiters AT, Siepel H (2010) Agri-environmental schemes for the Common hamster (Cricetus cricetus). Why is the Dutch project successful? Aspects Appl Biol 100:117-124

Luikart G, Allendorf FW, Cornuet JM, Sherwin WB (1998) Distortion of allele frequency distributions provides a test for recent population bottlenecks. J Hered 89:238-247

Matocq MD, Villablanca FX (2001) Low genetic diversity in an endangered species: recent or historic pattern? Biol Conserv 98:61-68

Mitchell-Jones AJ, Amori G, Bogdanowicz W (1999) The atlas of European mammals. Poyser, London

Müskens GJDM, Kats RJM, Kuiters AT (2008) Reintroduction of the Common hamster, Cricetus cricetus, in The Netherlands. Preliminary results. Proceedings of the $11^{\text {th }}, 14^{\text {th }}, 15^{\text {th }}$ meetings of the international Hamster workgroup; Budapest, Hungary (2003), Munsterschwarzach, Germany (2006) and Kerkrade, The Netherlands (2007). Wageningen/Nijmegen, The Netherlands

Nechay G (2000) Status of hamsters: Cricetus cricetus, Cricetus migratorius, Mesocricetus newtoni and other hamster species in Europe. Nature and Environment Series, no. 106. Council of Europe Publishing, Strasbourg

Nei M (1987) Molecular evolutionary genetics. Columbia University Press, New York

Neumann K, Jansman H (2004) Polymorphic microsatellites for the analysis of endangered Common hamster populations (Cricetus cricetus L.). Conserv Genet 5:127-130

Neumann K, Jansman H, Kayser A, Maak S, Gatterman R (2004) Multiple bottlenecks in threatened western European populations of the Common hamster Cricetus cricetus (L.). Conserv Genet 5:181-193 
Neumann K, Michaux R, Maak S, Jansman HAH, Kayser A, Mundt G, Gattermann R (2005) Genetic spatial structure of European Common hamsters (Cricetus cricetus) - a result of repeated range expansion and demographic bottlenecks. Mol Ecol 14:1473-1483

Pauly A (2007) Report on the status of the Common hamster (Cricetus cricetus) in Germany. Report published by the Council of Europe, Strasbourg

Peakall R, Smouse PR (2006) GENALEX 6: genetic analysis in Excel. Population genetic software for teaching and research. Mol Ecol Notes 6:288-295

Piry S, Luikart G, Cornuet JM (1999) BOTTLENECK: a computer program for detecting recent reductions in the effective population size using allele frequency data. J Hered 90:502-503

Pritchard J, Stephens M, Donnelly P (2000) Inference of population structure using multilocus genotype data. Genetics 155:945-959

Raymond M, Rousset F (1995) GENEPOP: population genetics software for exact tests and ecumenicism. Heredity 86:248-249

Robinson RA, Sutherland WJ (2002) Post-war changes in arable farming and biodiversity in Great Britain. J Appl Ecol 39:157-176

Sander M, Weinhold U (2008) The reintroduction project of Cricetus cricetus near the city of Mannhein, Baden-Württemberg, Germany-first results and experiences. In: Proceedings of the 11th, 14th, 15th Meeting of the International Hamster Workgroup;
Budapest, Hungary (2003), Munsterschwarzach, Germany (2006) and Kerkrade, The Netherlands (2007). Wageningen/ Nijmegen, The Netherlands

Tallmon DA, Luikart G, Waples RS (2004) The alluring simplicity and complex reality of genetic rescue. Trends Ecol Evol 19(9):489-496

Ulbrich K, Kayser A (2004) A risk analysis for the Common hamster (Cricetus cricetus). Biol Conserv 117:263-270

van Oosterhout C, Hutchinson WF, Wills DPM, Shipley P (2004) Microchecker: software for identifying and correcting genotyping errors in microsatellite data. Mol Ecol Notes 4:535-538

van Veen MP, Sanders ME, Tekelenburg A, Gerritsen AL, Lörzing JA, van den Brink TH (2010) Breaking boundaries for biodiversity. Expanding the policy agenda to halt biodiversity loss. Netherlands Environmental Assessment Agency PBL Den Haag/Bilthoven, The Netherlands

Verbist V (2008) Restocking and protection of the European hamster in Flanders, preliminary results. In: Proceedings of the 11th, 14th, 15th meeting of the international Hamster workgroup; Budapest, Hungary (2003), Munsterschwarzach, Germany (2006) and Kerkrade, The Netherlands (2007). Wageningen/ Nijmegen, The Netherlands

Wright S (1978) Evolution and the genetics of populations. IV. Variability within and among natural populations. University of Chicago Press, Chicago 